\title{
Análisis del fenómeno de las personas sin hogar en los medios de comunicación escrita mayoritarios. Una aproximación desde el análisis reticular del discurso.
}

Estíbaliz García Juan

Universidad Autónoma de Barcelona

\begin{abstract}
Resumen
La presente investigación se propone examinar algunos medios de prensa escrita de masas, en busca de el/los marco/s culturales utilizados para orientar, percibir, racionalizar y comprender el fenómeno del sinhogarismo; organizando y analizando el contenido de esto/s marco/s (conceptos, estereotipos, problemáticas asociadas, etc, y las relaciones entre ellos) en forma reticular.
\end{abstract}

Palabras clave: Marcos culturales - Redes - Sinhogarismo - Perspectiva reticular.

\begin{abstract}
The current investigation proposes the examination of parts of the written popular media, to look for cultural frameworks which guide and mould the perception, rationalisation and understanding of the social phenomenon of homelessness; organising and analysing the content of these frameworks (concepts, stereotypes, associated problems, etc, and the relationships between them) in a network perspective form.

Key words: Cultural frameworks - Networks - Homelessness - Network perspective.
\end{abstract}

\section{Introducción}

El objetivo y propósito que guió esta pequeña investigación desde el principio fue claro: el estudio de cómo se presenta en los medios de comunicación mayoritarios el sinhogarismo. Se propone entonces, realizar un estudio de la prensa escrita de masas, en la que se haga referencia directa al sinhogarismo. Ahora bien, desde la multitud de perspectivas teóricas y metodológicas desde las que se podría orientar este estudio, había dos aspectos clave de la investigación que se querían abarcar, y que marcaron la elección de la perspectiva reticular y los marcos culturales a la hora de tratar el tema.

En primer lugar, se quería dejar patente que la imagen que se proyecta en los medios de comunicación de determinadas problemáticas sociales, va más allá de ser un compartimento estanco de información recibida por un interlocutor (lector en este caso). Los marcos culturales ayudan a comprender cómo dentro del imaginario colectivo, se pueden encontrar una pluralidad de formas de racionalizar, organizar y representar diferentes problemáticas sociales, como el sinhogarismo. Como afirman Tábara, Costejá y van Woerden (Tábara et al., 2004: 158), la idea de marco cultural proporciona dos precondiciones básicas que pueden resultar especialmente 
interesantes: la primera es que no existe una única forma compartida por la totalidad de la sociedad de enfocar y pensar un fenómeno social; y la otra se centra en el hecho de encontrarnos frente a un fenómeno en que las dimensiones de lo político y lo social se entrecruzan, haciendo que no se puedan obviar las distribuciones de poder que afectan a estos fenómenos directamente, y a la forma en que son pensados y enfocados.

Por otra parte, el reconocimiento explícito de la posibilidad de esta multitud de marcos culturales y perspectivas socialmente compartidas sobre el sinhogarismo, caería en saco roto si no se contemplase también la pluralidad de fenómenos e ideas que pueden formarlo. En un mundo donde la complejidad de la esfera de lo social es cada vez más patente, la proposición es centrarse en la cantidad y no en la calidad. Es decir, ante objetos de estudio multidimensionales (con referencias a lo social, lo político, lo económico...), se puede optar por buscar pocos rasgos significativos para luego generalizarlos obviando el resto; o elegir perspectivas como la reticular, que permitan abarcar un gran número de ámbitos definitorios de un fenómeno, al centrarse en cómo las relaciones entre estas esferas conforman, en nuestro caso, un determinado marco cultural sobre el sinhogarismo. De ahí que como se puede entrever, se haya escogido la perspectiva reticular como forma de organizar el contenido de los marcos culturales que aspiramos a definir.

\section{Los marcos culturales y la perspectiva reticular}

Partiendo de la base de que como principal objetivo se planteó realizar un examen de los marcos culturales bajo los cuales se presenta el fenómeno del sinhogarismo en los medios de comunicación de masas, desde una perspectiva y metodología reticular; cabe tener en cuenta algunas consideraciones teóricas de base.

En un principio se aclarará qué se entiende por marco cultural, y en qué investigaciones previas se sustenta el análisis de este concepto. Más tarde se considerará el análisis reticular más que desde una perspectiva metodológica, como una nueva forma de orientar y organizar la teoría que permite enfocar una temática.

Una vez dejado claro que lo que interesa es la apreciación que se crea y se reproduce del sinhogarismo en los medios de comunicación mayoritarios, hay que preocuparse de: qué es exactamente esa "apreciación" que se intenta analizar. 
Partiendo de la misma base que lo hacen Joan David Tàbara, Meritxell Costejà y Fincent van Woerden en "Las culturas del agua en la prensa española. Los marcos culturales en la comunicación sobre el Plan Hidrológico Nacional"; se puede definir marco cultural como:

"un sistema coherente de elementos cognitivos y morales relativos a la forma de percibir, de racionalizar, de evaluar y de prescribir determinados fenómenos de la realidad social (...), de tal modo que se tornan significativos y memorables para los diferentes actores sociales en juego" (Tábara, Costejà, Van Woerden, 2004:154).

De forma que lo significativo de los marcos culturales, no es el contenido de la información en sí misma, sino cómo esta información se interpreta y presenta. Es decir, interesan los patrones que surgen alrededor de la exposición pública de un determinado fenómeno (el sinhogarismo en nuestro caso), y que debido al poder simbólico de los medios de comunicación a la hora de mostrar a gran escala sistemas de información coherentes; modelan las percepciones, los razonamientos, y el tipo de moral aplicada socialmente respecto del fenómeno social en cuestión. Hay que poner de relieve la importancia de considerar los discursos de estos medios de comunicación como sistemas de información y significado, dado que en ello se fundamenta el análisis reticular de los mismos. Este punto se desarrollará más adelante.

Ahora bien, el objetivo último de este informe es poner de relieve el o los marcos culturales mediante los cuales se percibe, se racionaliza y se reacciona ante el sinhogarismo. Todo ello se ha fundamentado, entonces, en una idea de los medios de comunicación de masas (de hecho, se han escogido los dos periódicos de prensa escrita de mayor tirada), como grandes generadores de opinión pública, y como gigantes precursores de diferentes marcos culturales mediante los que se entiende y percibe el sinhogarismo, y por tanto, que modelan y justifican las políticas y actuaciones sociales respecto del mismo, frente al resto de la sociedad.

Este punto resulta clave, para entender los procesos de acción y reacción colectiva ante fenómenos como el sinhogarismo; desde movimientos sociales, hasta ONGs, pasando por la misma opinión pública general. Las dinámicas sociales de estos diferentes colectivos se basan en definiciones claras de situaciones sociales. Por decirlo de otra forma, se necesita crear y recrear la definición social de determinado problema social, realizar un pronóstico del mismo, y generar motivación en los actores sociales para que éstos tomen parte en el mismo. En estos últimos puntos entran en juego los medios de comunicación y su poder simbólico. La sociología como disciplina, se ha preocupado en muchas ocasiones y desde diferentes 
enfoques, del estudio de la cultura así entendida y manejada por los actores sociales.

A este respecto resulta también muy interesante la concepción de Goffman de marco (Goffman, 1974, citado por Tábara et al., 2004:156), centrada en cómo los actores localizan, perciben, identifican y etiquetan la realidad; es decir, cómo estos actores justifican y recrean la realidad en la que viven conforme a patrones morales, éticos y cognitivos que guían su acción y acotan su propia percepción y racionalidad.

Por ello, una de las características de los marcos culturales, es en cierta forma, su performatividad. Tal y como se formula en "Las culturas del agua en la prensa española", los marcos culturales tienen ciertos rasgos fundamentales (Tábara et al., 2004: 158). El primer rasgo clave de los marcos culturales es la "perceptibilidad", es decir, hacen visibles dimensiones, rasgos o incluso fenómenos enteros, obviando e invisibilizando otros. Los marcos culturales dentro de los medios de comunicación, llegan incluso a incluir y excluir temáticas de las agendas políticas, en base a la acotación de los problemas que socialmente se presentan como acuciantes o preocupantes. Otra característica de los marcos culturales es la "racionalidad", dado que éstos promueven idearios lógicos y simbólicos mediante los cuales los sujetos piensan, ordenan y explican los fenómenos a los que se hace referencia. También resulta evidente la carga "moral" de los marcos culturales, dado que en toda definición de lo que algo es, entra lo que debería ser; y si los marcos culturales proveen del bagaje simbólico para "entender" un fenómeno, ello lleva imbuidas ciertas ideas morales de cómo ese fenómeno ha de ser juzgado. Por último está la "prescriptividad" de estos marcos, que se entiende de forma lógica una vez explicado cómo un marco cultural provee de herramientas lógicas y simbólicas de entendimiento de un fenómeno, guía la forma de juzgarlo moralmente, y por último prescribe ciertas pautas de acción y reacción ante el mismo.

Concretando, se realizará un estudio en dos medios de comunicación escrita de masas, dada su influencia para crear y modificar agendas de debates públicos que modelan las percepciones sociales de la realidad; y su poder para influenciar las opiniones, actitudes y estereotipos de las personas. A fin de cuentas, el interés en los medios de comunicación reside en su gran poder simbólico. Es decir, como apunta Martin W. Bauer en "Classical Content Analysis: a Review" (W. Bauer, 2000: 131), se estudiarán los medios de comunicación como "mediums of appeal", como grandes motores de creación y modificación de los marcos culturales de una sociedad. 
En la segunda parte de este pequeño apartado de aclaraciones teóricas, me limitaré a intentar responder a la pregunta de porqué organizar el contenido de un marco teórico de forma reticular.

Decir que lo que verdaderamente resulta interesante de esta perspectiva reticular a la hora de abordar un análisis de contenidos de los medios de comunicación, estriba en que permite prestar atención a las relaciones y co-presencias que se realizan en los artículos seleccionados. Dicho de otra forma, se pretende que emerjan marcos culturales prestando atención a las relaciones y coherencia entre los fenómenos que se presentan unidos, y no tanto realizar un estudio en profundidad de las temáticas perfectamente acotadas que puedan surgir. El énfasis se pone en la mayor identificación posible de asuntos en la configuración de marcos culturales que hablen de qué se relaciona con sinhogarismo, en la consecución de una red que describa qué fenómenos concuerdan con el sinhogarismo en estos dos medios de comunicación; y no en realizar un decálogo en profundidad de cuatro asuntos que aparezcan junto al sinhogarismo en los medios. Se trata de "no quedarse en la categorización del texto como la exclusiva manera de descubrir el sentido del discurso " (Lozares, Verd, Martì, López, 2003:27), de utilizar e interpretar las relaciones que surgen entre nodos y categorías emergentes para enunciar y definir los marcos culturales que surjan.

Entonces, un asunto resultará relevante no por su contenido teórico-sociológico, sino que la relevancia la marca la relación de co-presencia con la problemática de las personas sin hogar en la prensa escrita mayoritaria. Teniendo en cuenta el poder simbólico de los medios de comunicación en lo referente al imaginario colectivo que se comparte sobre sinhogarismo en nuestras sociedades; el análisis de los mismos, permitirá saber qué fenómenos sociales se entrelazan y relacionan en este imaginario sobre las personas sin hogar. Es decir, el análisis reticular de los marcos culturales referentes al sinhogarismo, consistiría entonces en la concordancia en un mismo discurso de diferentes temáticas, que cobran importancia más que por sí mismas, por sus interrelaciones entre ellas y con el sinhogarismo; y que conforman esos "patrones relativamente coherentes de percepción, de moralidad y de razonamiento" (W.Bauer, 2.000: 131). relacionados con este fenómeno. Tal y como explica W.Bauer:

"El AC [Análisis de Contenidos] puede reconstruir los "mapas de conocimiento" contenidos en textos. Las personas utilizamos el lenguaje para representar el mundo que nos rodea, como conocimiento general y como conocimiento sobre nosotros mismos. Para reconstruir este conocimiento, el AC tiene que ir más allá de la clasificación de las unidades textuales, y trabajar en la formación de redes compuestas por unidades de análisis para 
representar no sólo los elementos de dicho conocimiento, sino también las relaciones entre éstos [elementos]" (W.Bauer, 2.000: 135) ${ }^{1}$.

Se podría decir, que lo que interesa es trazar pequeños "mapas de conocimiento" culturales (en palabras de Bauer) imbuidos en los medios de comunicación seleccionados, sobre el sinhogarismo.

Llegados a este punto, la siguiente pregunta resultaría de pensar en por qué una perspectiva reticular de este tipo resultaría interesante para abordar el estudio de los marcos culturales. La respuesta es aún más simple: por una parte, un marco cultural conforma un concepto interesante por la generalidad de la idea, por su capacidad de embotar múltiples dimensiones culturales en un mismo marco, que proporcione un contexto cultural adecuado bajo el cual entender un fenómeno. Formular el marco cultural bajo múltiples fenómenos o dimensiones estudiados en profundidad y acotados bajo categorías distintas, no ofrecería una visión lo suficientemente amplia. Profunda sí, en tanto que acota y define cada categoría cultural por sí misma y en sus atributos con detallismo. Pero se perdería de vista la visión amplia y general básica, en que se fundamenta la idea de marco cultural; algo que no ocurre si se analizan los marcos culturales bajo una perspectiva reticular mucho más amplia y relacional.

Por otra parte, los marcos culturales se basan en la congruencia de muchas dimensiones y pautas culturales, lo suficientemente homogéneas como para formar un marco de entendimiento. Por lo tanto, el aspecto clave es qué tienen en común estas pautas o conceptos culturales como para formar un marco. Al hablar de aspectos en común, se hace referencia a aspectos culturales compartidos lo suficientemente como para formar un marco; no tiene sentido el estudio en profundidad de cada uno de estos aspectos por separado. La perspectiva reticular es la que propicia el estudio de cómo estos aspectos se presentan conjuntamente en un fenómeno, porque es la única que estudia las relaciones mismas entre categorías culturales. Permite analizar las co-presencias de estos aspectos culturales en los medios de comunciación, y si éstos están lo suficientemente relacionados y presentes como para hablar de marcos culturales. Tal y como describe Robert A. Hanneman en "Introducción a los métodos del análisis de redes sociales"( Hanneman, 2000):

\footnotetext{
${ }^{1}$ Traducción libre.
} 
"El análisis estructural no se interesa particularmente por estos sistemas de categorías (o variables) que se basan en descripciones de atributos individuales similares (...). Los analistas estructurales intentan definir categorías y variables en términos de similitud de los modelos de relaciones entre los actores, en lugar de definirlas respecto a los atributos de los actores. Es decir, la definición de una categoría, (...) depende de sus relaciones con otra categoría" (Hanneman, 2000: 4).

Se comprende, entonces, la necesidad y relevancia de utilizar la perspectiva y análisis reticular para entender y estudiar los marcos culturales. $Y$ además, formular y organizar este conocimiento, en forma de una red $\operatorname{cognitiva}^{2}$; a partir de determinados discursos formulados en determinados medios de comunicación. De esta forma, a partir de la perspectiva reticular de análisis, la misma definición de discurso podría sufrir cambios. Desde este punto de vista, el discurso debería ser considerado, en palabras de Carlos Lozares como "un tejido de relaciones formado por lazos y conexiones de sigfinicados en y entre las diferentes unidades que se consideren" (Lozares, 2000: 184).

Queda, entonces, lo suficientemente conceptualizado el porqué de un análisis del discurso en los medios de comunicación de masas sobre el sinhogarismo, en base a la emergencia de marcos culturales a la hora del tratamiento de la temática.

\section{Consideraciones metodológicas previas}

Antes de proseguir con el contenido y resultados de este pequeño estudio, se hace necesario aclarar ciertos puntos clave tanto en lo referente a la metodología, como en referencia a las decisiones básicas que acotan el objeto de estudio.

Tal y como se apuntó anteriormente, el propósito básico de esta investigación consiste en realizar un estudio de los medios de comunicación de masas; más concretamente, de los grandes medios de prensa escrita. La razón resulta obvia, ya que debido a la metodología que se utilizará, la forma que se tiene de establecer la relación entre dos códigos o asuntos tratados en los medios, es su copresencia dentro de un mismo discurso. El formato de la prensa escrita y su estructuración

\footnotetext{
2 Utilizaremos como definición de red cognitiva, la siguiente: "Una estructura de nodos y lazos útil para representar un conocimiento. Los nodos representan conceptos, atributos, estados o acontecimientos; y los lazos representan las relaciones existentes entre los nodos" (Lozares, Verd, Martì, López, 2003:10).
} 
en artículos acotados perfectamente por asuntos y acontecimientos, ofrece el material perfecto para realizar el estudio en cuestión.

Ahora bien, no todos los medios tienen la misma cobertura y alcance, e interesa exactamente que su influencia sea lo más elevada posible; dado que hablar de marcos culturales en base a los datos obtenidos del análisis solo puede hacerse bajo el supuesto de que estos medios tengan la influencia suficiente como para conformar dichos marcos de una forma significativa.

Por ello se siguieron dos criterios principales a la hora de escoger los medios de comunicación de prensa escrita a analizar:

- Elegir dos medios a poder ser de ideología diferente (lo que pueda abrir la puerta a encontrar más de un marco cultural de referencia y orientación de la información).

- Escoger medios de comunicación masivos, con gran influencia, lo cual garantizaría que las posibles pautas y enfoques de la temática encontrados, tuviesen suficiente influencia social como para hablar de marcos culturales.

Tampoco se puede olvidar que el tiempo escogido también delimita el objeto de investigación. En este caso se buscó primar dos aspectos, por una parte englobar dentro del objeto algunas noticias relacionadas con el debate de la ordenanza de civismo en Barcelona, en la que el pernoctar en espacios públicos constituía una acción "incívica"; y delimitar un tiempo que permitiese obtener una cantidad de artículos manejable, en una investigación de bajas aspiraciones como es esta. Por ello se escogió del 1 de noviembre de 2005, hasta el 31 de Febrero de 2006: queda cubierto en un espacio de cuatro meses parte del debate de dicha ordenanza; además del resto de artículos y noticias presentes en relación al sinhogarismo, en un ámbito temporal amplio pero manejable.

Una vez aclarados los criterios de elección, decir que tras la consulta en la Oficina de Justificación de la Difusión (OJD), se obtuvieron los datos de las tiradas de los principales periódicos a nivel estatal a fecha de 2.005. De esta forma se escogieron los dos periódicos con tiradas superiores al resto, y que suelen ser asociados con ideologías diferentes: El País, con 450.000 ejemplares vendidos estimados; y El Mundo S. Veintiuno, con una tirada de 315.000 ejemplares.

Por otra parte, no se debe obviar que el punto de referencia básico del objeto de estudio es el sinhogarismo; además de ser el motor de búsqueda y selección de los 
artículos a analizar. Por lo que un aspecto de vital importancia que dará forma a este pequeño estudio, será qué se entendiende por sinhogarismo.

Como sucede en la mayor parte de las ciencias sociales, el objeto y conceptos que se manejan desde la sociología tienen su reflejo en la vida social que aspiran a analizar. Toda persona que decida realizar un estudio que aspire a calificarse de sociológico, ha de saber que se encuentra frente a un objeto de estudio pensante, que representa y da significados a la realidad que le rodea, y esto incluye su "realidad social", la misma que el sociólogo aspira a estudiar. Por ello, mucha de la terminología utilizada en sociología en ocasiones coincide o hace referencia a fenómenos de los que "la sociedad" tiene ya cierta idea preconcebida. Y esta "idea" de base, puede dar rienda suelta a los estereotipos y etiquetas sociales que se suelen utilizar frente a determinados grupos, incluido claro está el de las personas sin hogar. El dilema que tendemos entre manos, es ni más ni menos, que el de empezar una investigación evitando en la medida de lo posible los sesgos ideológicos y sociales.

Este punto es especialmente relevante a la hora de acotar objetos de estudio y aportar definiciones sociológicas; y es uno de los aspectos clave a los que se tuvo que enfrentar este pequeño estudio en su fase inicial, dado que se tenían que delimitar palabras que ejerciesen de motores de búsqueda para seleccionar los artículos que hiciesen referencia al sinhogarismo. En resumidas cuentas, para buscar los artículos a analizar, se necesitaban palabras y conceptos que definiesen el sinhogarismo tal y como se maneja el concepto socialmente (que no sociológicamente), para que guiasen la selección de artículos a analizar.

En un principio la mayor preocupación fue encontrar una definición de sinhogarismo "sociológica", o que generase cierto consenso dentro de la comunidad sociológica que se ocupa de analizarlo. Desde esta perspectiva, básicamente se podría entender por persona sin hogar:

"Personas que no pueden acceder o conservar un alojamiento adecuado, adaptado a su situación personal, permanente y que proporcione un marco estable de convivencia "(Avramov, 1995).

Sin ánimo de entrar en el amplio e interesante debate sobre la envergadura y contenido del concepto de sinhogarismo, se aceptará uno de los intentos más fructíferos de definir el término: el European Obeservatory de FEANTSA (European Federation of Organizations Working with the Homeless) ha construido una tipología sobre la exclusión residencial que resulta muy ilustrativa y operativamente muy útil. A partir de tres dimensiones o dominios que consideran básicos a la hora de 
poder hablar de una situación de sinhogarismo (el dominio físico o una "casa" que cumpla ciertos mínimos de habitabilidad, el dominio social referente al hogar como retículo socio-afectivo, y el dominio legal que habla del título legal y de tenencia del habitáculo), se ha construido toda una rejilla de hasta trece subcategorías relativas a diferentes situaciones y grados de exclusión residencial (Cabrera, Rubio, 1998). Dentro de la complejidad de esta tipología exhaustiva, este análisis se centrará en las cuatro categorías básicas, que aglutinan las trece anteriores, y que resultan realmente útiles gracias a su capacidad de síntesis de lo que el sinhogarismo puede llegar a significar:

- Sin techo (Rooflessness): personas que pernoctan en espacios públicos y exteriores, o en albergues nocturnos.

- Sin vivienda (Houselessness): personas que habitan en alojamientos, albergues y centros de acogida temporales, ya sean dependientes de instituciones públicas sanitarias o penales, o espacios para colectivos delimitados (centros de menores, de mujeres, para personas sin hogar...)

- Vivienda insegura (Insecure housing): personas cuyo régimen de tenencia sea inseguro, bajo amenaza de desahucio, que viven acogidas por familiares y redes informales de apoyo, o bajo la amenaza de violencia.

- Vivienda inadecuada (Inadequate Housing): personas que viven en condiciones de hacinamiento, en alojamientos impropios, o en habitáculos no convencionales (chabolismo, caravanas...).

Tras una breve ojeada al alcance del sinhogarismo sociológicamente entendido, gracias al ETHOS ("Tipología europea sobre el sinhogarismo y la exclusión residencial") europeo, resulta patente que el fenómeno de la exclusión residencial abarca una multitud de situaciones y dimensiones de vulnerabilidad que exceden lo que en ocasiones se entiende socialmente por persona sin hogar. De hecho Pedro José Cabrera (Cabrera, 2008: 16), llega a hablar de la carga política que sostiene una definición más restrictiva o más amplia que se pueda tener sobre el sinhogarismo; desde a la hora de cuantificar el fenómeno como a la hora de diseñar el alcance de las políticas públicas. Resulta evidente que a una definición más amplia se tenga del fenómeno, más se debería ampliar su repercusión social, el peso numérico del colectivo, y más debieran aumentar los recursos y políticas sociales al respecto. 
Pues bien, si esto parece relevante para plantear este estudio, es porque en la fase inicial de búsqueda de artículos en base a palabras clave, no se encontraron casi registros referentes a la nomenclatura utilizada anteriormente para hablar de sinhogarismo, es decir, en base al lenguaje sociológico: sinhogarismo, sin hogar, sin techo, sin vivienda... Como se especificará más adelante, tras una primera búsqueda aleatoria en la prensa, queda claro que los términos, y la idea, con la que aparece el fenómeno del sinhogarismo en la prensa de masas dista mucho de esta definición y concepto. De hecho, los términos bajo los cuales se hacía referencia al sinhogarismo tenían una gran carga estereotipada, y reducían el fenómeno del sinhogarismo a lo que en el ETHOS europeo abarcaría únicamente la primera tipología de persona sin hogar: "sin techo". Se afirma esto, porque, una vez desterrada la nomenclatura y forma sociológica de tratar el fenómeno, se optó por el siguiente proceso, intentando acercar más la investigación al imaginario social de fondo (el cual es el objeto de estudio final de los marcos culturales).

Entonces para determinar los términos que se utilizarían como motores de búsqueda, se consultaron diferentes sinónimos y definiciones aplicables a las personas en situación de sinhogarismo. De ahí resultó la segunda forma de enfocar el sinhogarismo. Si el ETHOS europeo se asemejaría a la visión sociológica, los diccionarios de sinónimos "Wordreference" y el de la Real Academia de la Lengua Española, proveerían de la visión "popular" u "oficialista" de la temática. Decir que ni "sin hogar", ni "sin techo", ni "sinhogar" ni "sintecho", aparecen en ninguno de estos dos diccionarios. Parecen ser parte de la jerga sociológica para determinar el fenómeno. En el cuadro 1 se aprecia cómo la búsqueda bajo los términos "sintecho" y "sinhogar" fue infructuosa en ambos periódicos. Los vocablos "sin techo" y "sin hogar" ${ }^{\prime 3}$ ofrecen cifras de presencia sospechosamente altas, por lo que me permito dudar de si son utilizados en relación al sinhogarismo en alguna de sus formas ("sin" por una parte y "hogar" o "techo" por otra), o como parte de expresiones y contextos no relacionados con la temática.

En una primera aproximación al sinhogarismo y en una búsqueda exploratoria, se pudo constatar cómo los conceptos que más aparecían en la prensa eran las

\footnotetext{
${ }^{3}$ La búsqueda se realizó como todas las demás, en el titular y subtítulo o entradilla de los artículos, pero se especificó que se buscasen las expresiones literales "sin techo" y "sin hogar" (con comillas) para reducir el número de registros-paja, que aún así, sospechamos, son ingentes. Razón por la cual se ha optado por eliminarlos de la búsqueda, además de por su baja utilización en el habla común para referirse al fenómeno que nos interesa.
} 
categorías de "vagabundo/s", "mendigo/s" y "indigente/s". Para garantizar la centralidad de la temática sinhogar en los artículos encontrados (y ofrecer cifras fehacientes) las búsquedas se realizaron en base a la presencia de alguno de los siguientes términos en los titulares y subtítulos de las noticias ( $y$ no en base a la presencia de estos vocablos en todo el texto): Vagabundo, vagabundos, mendigo, mendigos, indigente, indigentes. Se evita así la contabilización de los registrospaja: presencia de las palabras seleccionadas en expresiones lingüísticas (muy común si realizabamos la búsqueda con el término "sin")... Por esta razón se eliminaron de la búsqueda las expresiones "sin hogar" o "sin techo", para evitar que la búsqueda se llenase de artículos que únicamente presentaban los vocablos "sin", "hogar" o "techo", cuyos significados por sí mismos no interesan como motores de búsqueda y solo introducirían registros ruido que complicarían el análisis y falsearían los datos.

Tabla 1: Fuente: Elaboración propia.

\begin{tabular}{|c|c|c|c|c|}
\hline & Sin hogar & Sinhogar & Sin techo & Sintecho \\
\hline El País & 28 & 0 & 33 & 0 \\
\hline EI Mundo & 12 & 0 & 32 & 0 \\
\hline
\end{tabular}

Tabla 2: Fuente: Elaboración propia.

\begin{tabular}{|c|c|c|c|c|c|c|}
\hline & Vagabundo & Vagabundos & Mendigo & Mendigos & Indigente & Indigentes \\
\hline EI País & 0 & 0 & 5 & 4 & 9 & 5 \\
\hline EI Mundo & 4 & 2 & 7 & 11 & 37 & 3 \\
\hline
\end{tabular}

Se decidió entonces, como se ha apuntado, centrar la búsqueda bajo los siguientes parámetros: la presencia de alguna de estas palabras en los registros encontrados: vagabundo, vagabundos, mendigo, mendigos, indigente, indigentes.

En la siguiente tabla se ofrecen los resultados de las búsquedas que se realizaron, para comprender cómo varían los registros finales en base a los criterios antes comentados:

Tabla 3: Fuente: Elaboración propia.

\begin{tabular}{|l|c|c|c|c|}
\hline & \multicolumn{2}{|c|}{ Búsqueda en todo el artículo } & \multicolumn{2}{c|}{$\begin{array}{c}\text { Búsqueda en el titular y en el } \\
\text { subtítulo }\end{array}$} \\
\hline & Con registros & Sin registros & Con registros & Sin registros \\
\hline
\end{tabular}




\begin{tabular}{|c|c|c|c|c|}
\hline & "paja" & "paja" & "paja" & "paja" \\
\hline EI País & +6004 & 143 & 83 & 22 \\
\hline EI Mundo & 593 & 135 & 91 & 49 \\
\hline
\end{tabular}

Evidentemente, sobra decir que la búsqueda que se aceptará, y los registros propuestos para guiar el análisis, son los presentes en la columna de "sin registros paja", dentro del conjunto de "búsqueda en el titular y en el subtítulo". Parece plausible que resultarán artículos lo suficientemente centrados en la temática del sinhogarismo como para analizarlos con el objetivo de la investigación.

Ahora bien, como se comentó con anterioridad, queda por responder la pregunta de por qué centrarse en los términos de búsqueda antes citados, como supuestos ejemplos de la concepción "común" o socialmente aceptada de sinhogarismo y personas sin hogar. Resulta sumamente útil consultar diccionarios convencionales para acceder a la definición y contenido de las palabras en una versión socialmente "oficialista" de determinados fenómenos. Se optó por consultar diccionarios de sinónimos para dar con las palabras que plausiblemente podrían ser utilizadas para nombrar el sinhogarismo (visto el escaso éxito que se obtuvo en un principio orientando la búsqueda sociológicamente, con "sinhogar", "sintecho", "sin hogar" o "sin techo"). Se fueron entrelazando términos y se optó por los siguientes:

- Mendigo: Mendicante, pobre, pordiosero, necesitados, indigente, menesteroso.

- Indigente: Pobre, mendigo, menesteroso, necesitado, paupérrimo, arruinado, vagabundo, miserable.

- Vagabundo: holgazán, trotamundos, vago, perezoso, bohemio, errante, ambulante, pícaro, golfante.

Se creó una cadena de tres vocablos, cargados además de estereotipos fácilmente identificables, gracias al contenido de los sinónimos que se proponían en Wordreference.com. Se desechó de la búsqueda el resto de sinónimos propuestos por el diccionario, al considerarlos poco precisos, ambiguos o que no se ceñían exclusivamente al fenómeno que nos interesaba (previa consulta en el diccionario de la Real Academia de la Lengua Española).

\footnotetext{
${ }^{4} 600$ artículos es el máximo de búsqueda que aceptaba el proceso utilizado.
} 
Otro punto realmente interesante para saber la carga simbólica de cada uno de estos tres términos, fue la consulta de los mismos en el citado diccionario de la Real Academia Española de la Lengua. Se obtuvo lo siguiente:

- Mendigo: Persona que habitualmente pide limosna.

- Indigente: Que padece indigencia [definiendo indigencia como: falta de medios para alimentarse, vestirse, etc].

- Vagabundo: 1.- Que anda errante de una parte a otra.

2.- Holgazán u ocioso que anda de un lugar a otro, sin tener oficio ni domicilio determinado.

Si ya es llamativa la inexistencia del uso de palabras como "sinhogar" o "sintecho" o "sinhogarismo" para hablar de las personas que sufren exclusión residencial, la carga subjetiva de los términos encontrados para referirse al fenómeno en cuestión puede ser bastante fuerte. Además, las formas encontradas de referirse al sinhogarismo, reducían su contenido a lo que según el ETHOS europeo sería únicamente la primera tipología de personas que sufren la exclusión residencial: las personas "sin techo". Se acepta por lo tanto, otra limitación dentro de este pequeño estudio: a pesar de que en un principio se pretendió abarcar una definición sociológica del sinhogarismo, que diese cuenta del amplio espectro de situaciones de exclusión residencial; se tuvo que ceñir al estudio a las personas "sin techo" según el ETHOS europeo, dado que no se detectó dentro de los dos medios de prensa escrita seleccionados, una concepción del sinhogarismo más amplia.

Una vez delimitado el objeto de estudio, y el procedimiento de selección de los artículos a analizar; se hace necesario aclarar ciertos puntos metodológicos del análisis. Decir que básicamente, el esquema metodológico emerge en dos etapas. Primero se propone la obtención de los códigos o asuntos básicos tratados en cada uno de los textos, en base al Análisis de Contenido; para luego organizarlos en forma redes y analizarlos desde una perspectiva reticular que permita obtener dos redes sociométricas representativas de cada uno de los periódicos seleccionados.

Primero se comentará la que sería la primera etapa del análisis: el análisis de los datos textuales conforme a los principios del Análisis de Contenido. Se ha propuesto este método de análisis para el estudio que se propone, puesto que facilita la creación de un sistema de códigos que permita acceder a patrones explicativos generados a partir de los diferentes textos que conforman nuestra muestra, de una 
forma sistemática y delimitada que guíe el proceso y permita la comparación de casos. Se podría decir que esta metodología afianza las condiciones para un análisis de redes posterior, compatibilizando estos dos métodos de investigación.

Concretamente, dado el manifiesto interés en los marcos culturales, esta metodología, permitirá el estudio del contexto cultural que rodea a un determinado texto/s: "[El análisis de contenido] es una técnica que permite realizar inferirencias del contexto social a partir de un texto concreto de forma objetiva" (W.Bauer, Martin, 2000: 133) ${ }^{5}$. En pocas palabras, el Análisis de Contenidos, permite crear sistemas de codificación así como categorías, que permitan el análisis de textos de prensa como objeto de investigación para acceder los patrones, estereotipos, valores, prejuicios, opiniones, actitudes y marcos de referencia e interpretación, que conforman los marcos culturales con los que los actores dan significación y orientan sus experiencias. Como afirma Philipp Mayring: "El objetivo del Análisis de Contenidos es el examen sistemático de material comunicativo (originalmente proveniente de un medio de comunicación de masas concreto)" (Mayring, 2004: $\left.{ }^{266}\right)^{6}$; y si precisamente existe un objetivo claro en la investigación, ese es el estudio sistemático del material comunicativo respecto del sinhogarismo, reproducido por los mass media. El esquema del procedimiento que guiará el análisis será el siguiente:

\footnotetext{
${ }^{5}$ Traducción libre.

${ }^{6}$ Traducción libre.
} 


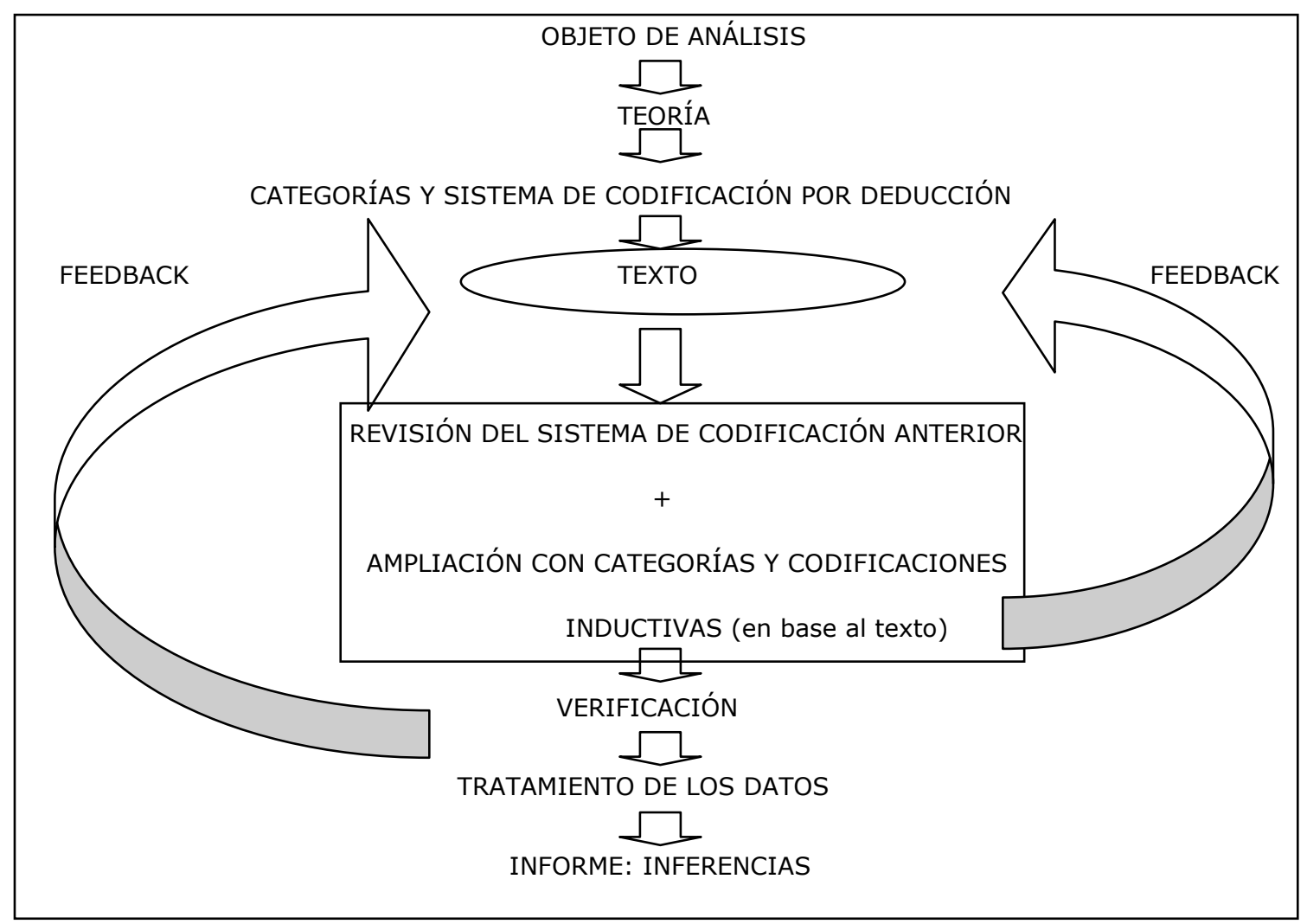

Fuente: Elaboración propia.

Por otra parte, la segunda etapa por la que discurrirá el proceso es el análisis reticular de los datos textuales (códigos) obtenidos en el paso anterior. Teniendo en cuenta que ya se ha hablado de los beneficios y adecuación de la perspectiva reticular, especialmente dado el propósito del estudio; en este apartado simplemente se puntualizará que la propuesta de investigación, es la articulación de una red de conceptos en base al análisis de la prensa escrita. La proposición consiste en la creación de dos redes contiguas, cada una representativa de la visión de un periódico, y bajo la suposición inicial de la existencia de dos marcos culturales diferentes a la hora de tratar el tema del sinhogarismo. La investigación pasaría por constatar precisamente si se puede hablar de la existencia de uno o más marcos culturales, es decir, si hay diferencias significativas en la forma de articular el discurso y de orientar y racionalizar el fenómeno del sinhogarismo, entre ambos medios de comunicación.

Para proponer el análisis de los marcos culturales bajo una estructura reticular, se parte de visiones como la de Jaime Andréu Abela en "Las técnicas de Análisis de Contenido: una revisión actualizada", en la que habla del modelo del "Análisis de Contenido de Redes" bajo los siguientes términos: 
"Red léxica ideológicamente significativa que impregna el discurso, se identifica sobre la base de la reiteración y da como resultado un esquema de la organización semántica de este discurso en forma de red" (Abela, 1998).

La propuesta consiste en desvelar la red léxico-semántica referente al sinhogarismo, presente en estos dos periódicos, para concluir más adelante si subyace un mismo marco cultural, o dos diferentes (uno por periódico), a la hora de tratar esta temática en estos dos medios. Bajo esta premisa, cabe reiterar que el análisis reticular resulta interesante precisamiente porque permite contextualizar y poner en relación diversos aspectos que se pueden encontrar en los marcos culturales. Dicho de otra forma, no interesan los componentes de un marco por sí mismos, si no en la medida en la que están copresentes en un mismo discurso; porque éste punto es el que hace de los marcos culturales entidades complejas formadas por fenómenos relacionados entre sí. Tal y como afirma Joan Miquel Verd en "El uso de la teoría de redes sociales en la representación y análisis de textos. De las redes semánticas al análisis de redes textuales": "el significado de un texto se obtiene poniendo el acento tanto en los nodos como en las relaciones que los vinculan" (Verd,2005: 138). De ahí la importacia del uso de la metodología de redes para el estudio de los marcos culturales, unos marcos formados por pequeños fenómenos que toman fuerza y sigificación por el hecho de aparecer juntos en lo referente a determinado fenómeno social y cultural.

\section{Primera etapa del análisis: el Análisis de Contenidos}

Tal y como sucede en todo Análisis de Contenidos, la codificación adquirió un papel central en todo el proceso. El propio Martin W.Bauer puntualiza que la codificación y clasificación del material seleccionado, es una tarea constructiva que hace de puente entre la propia teoría y el material objeto de investigación empírica (Bauer, 2000). En este apartado se intentará, entonces, trazar y explicar cómo "surge" este puente en el caso que nos ocupa. Es necesario remarcar este aspecto, ya que la propia metodología propuesta se fundamenta en el posterior análisis reticular de los códigos emergentes en el análisis, por lo que este proceso gana relevancia.

De esta forma, se le dará una importancia inicial y básica al análisis de los códigos que han ido surgiendo durante el proceso de análisis. Por ello, se propuso la elaboración de las dos tablas que se adjuntan (tablas 4 y 5), con la información 
básica de los códigos obtenidos, y la importancia total y relativa (en relación a la totalidad de las codificaciones realizadas en cada periódico) de cada uno de éstos.

En primer lugar se comparan las formas que en ambos periódicos tenían de referirse al objeto de estudio: el sinhogarismo. A la hora de referirse a las personas sin hogar, se han encontrado múltiples acepciones y formas de tratar el tema, cada una con su propio contenido connotativo asociado, tal y como se pudo ver en el punto anterior.

Lo primero que salta a la vista, es que El Mundo tiene un espectro mucho más amplio que El País para etiquetar a las personas sin hogar: "Sin techo", "Homeless", "Indigente/s, indigencia...", "mendigo/s, mendicidad..." o "vagabundo/s, vagabundear..."; siendo las categorías más utilizadas las de "indigente/s, indigencia..." o "mendigo/s, mendicidad...", aunque también cobra fuerza el hecho de recurrir a "vagabundo" para hablar de este fenómeno. Remarcar de nuevo que aunque en contadas ocasiones, El Mundo utilizaba jerga como la utilizada en el ámbito sociológico para hablar de sinhogarismo, como "sin techo" o "homeless". Éstas son categorías cargadas en una menor connotación dentro de la opinión pública, y que aluden menos a estereotipos marcados sobre el sinhogarismo.

Tabla 4: Fuente: Elaboración propia.

\begin{tabular}{|c|c|c|}
\hline CóDIGOS DE ANÁLISIS DE EL MUNDO & $\begin{array}{c}\text { Frecuencias } \\
\text { absolutas }\end{array}$ & $\begin{array}{c}\text { Frecuencias } \\
\text { relativas }\end{array}$ \\
\hline "Sin techo" & 5 & $1,29 \%$ \\
\hline Acoso a Sinhogar & 26 & $6,70 \%$ \\
\hline Alcoholismo, alcohol & 16 & $4,12 \%$ \\
\hline Asesinato de un sinhogar & 30 & $7,73 \%$ \\
\hline Barcelona & 31 & $7,99 \%$ \\
\hline Centro de acogida o atención para sinhogar: albergues... & 5 & $1,29 \%$ \\
\hline Cultura urbana & 3 & $0,77 \%$ \\
\hline Descripción del asesinato, acoso, muerte. & 21 & $5,41 \%$ \\
\hline Drogas (excepto alcohol) & 4 & $1,03 \%$ \\
\hline Exclusión social & 13 & $3,35 \%$ \\
\hline Homeless & 1 & $0,26 \%$ \\
\hline Incivismo & 3 & $0,77 \%$ \\
\hline Indigente/s, indigencia... & 35 & $9,02 \%$ \\
\hline Inmigrante/s, extranjería & 6 & $1,55 \%$ \\
\hline Jóvenes o menores de edad & 36 & $9,28 \%$ \\
\hline Mendigo/s, mendicidad... & 27 & $6,96 \%$ \\
\hline Movimientos de ultraderecha & 6 & $1,55 \%$ \\
\hline Muerte de persona sinhogar & 3 & $0,77 \%$ \\
\hline ONGs y entidades de atención a sinhogar & 3 & $0,77 \%$ \\
\hline
\end{tabular}




\begin{tabular}{|c|l|l|}
\hline Ordenanza civismo municipal (Barcelona) & 3 & $0,77 \%$ \\
\hline Perfil de los acusados, agresores... & 14 & $3,61 \%$ \\
\hline Perfil de sinhogar & 4 & $1,03 \%$ \\
\hline Pobreza & 9 & $2,32 \%$ \\
\hline Proceso judicial por asesinato de un/a sinhogar & 8 & $2,06 \%$ \\
\hline Prostitución & 5 & $1,29 \%$ \\
\hline Rechazo institucional & 5 & $1,29 \%$ \\
\hline Reconocimiento institucional & 3 & $0,77 \%$ \\
\hline Sagabundo/a, vagabundear... & 4 & $1,03 \%$ \\
\hline Vecinos, movimientos vecinales & 14 & $3,61 \%$ \\
\hline Violencia juvenil & 9 & $2,32 \%$ \\
\hline TOTALES & 36 & $9,28 \%$ \\
\hline
\end{tabular}

Algo que no ocurre con El País, que recurre para hablar de sinhogarismo casi en exclusiva, a las etiquetas de "indigente" y "mendigo"; términos que como se vio anteriormente, tienen una gran carga subjetiva dentro del contexto social y que recrean cierta estereotipación social del fenómeno. De todas formas, ambos medios de comunicación utilizan mayoritariamente las ideas de indigencia y mendicidad para referirse al sinhogarismo en la mayoría de casos, ello se ilustra en que estos códigos, en ambos medios, son de los códigos con más presencia relativa (obsérvense los porcentajes de cada código). Este punto informa de la existencia de un estereotipo claro promulgado y realimentado por los medios de comunicación, respecto a las personas sin hogar: el del mendigo e indigente. Volviendo de nuevo a las definiciones que manejábamos anteriormente, el contenido de estas ideas sociales bien podría ser el de mendigo como "mendicante, pobre, pordiosero, necesitados, indigente, menesteroso"; e indigente definido en términos de "pobre, mendigo, menesteroso, necesitado, paupérrimo, arruinado, vagabundo, miserable". 
Tabla 5: Fuente: Elaboración propia.

\begin{tabular}{|c|c|c|}
\hline CódIGOS DE ANÁLISIS DE EL PAÍS & $\begin{array}{c}\text { Frecuencias } \\
\text { absolutas }\end{array}$ & $\begin{array}{c}\text { Frecuencias } \\
\text { relativas }\end{array}$ \\
\hline Acoso a sinhogar & 8 & $6,02 \%$ \\
\hline Alcoholismo & 3 & $2,26 \%$ \\
\hline Asesinato de un sinhogar & 6 & $4,51 \%$ \\
\hline Barcelona & 11 & $8,27 \%$ \\
\hline Centro de acogida o atención para sinhogar: albergues... & 6 & $4,51 \%$ \\
\hline Drogas (excepto alcohol) & 3 & $2,26 \%$ \\
\hline Estafa & 2 & $1,50 \%$ \\
\hline Incivismo & 3 & $2,26 \%$ \\
\hline Indigente/s, indigencia... & 19 & $14,29 \%$ \\
\hline Indocumentación, "sin papeles" & 3 & $2,26 \%$ \\
\hline Inmigrante/s, extranjería & 3 & $2,26 \%$ \\
\hline Jóvenes o menores de edad & 11 & $8,27 \%$ \\
\hline Mendigo/s, mendicidad... & 14 & $10,53 \%$ \\
\hline Muerte de persona sinhogar & 2 & $1,50 \%$ \\
\hline Narcosala & 2 & $1,50 \%$ \\
\hline Ordenanza civismo municipal (Barcelona) & 3 & $2,26 \%$ \\
\hline ONGs y entidades de atención a sinhogar & 2 & $1,50 \%$ \\
\hline Perfil de sinhogar & 2 & $1,50 \%$ \\
\hline Perfil de los acusados, agresores... & 1 & $0,75 \%$ \\
\hline Pobreza & 1 & $0,75 \%$ \\
\hline Proceso judicial por acoso y violencia contra un/a sinhogar & 1 & $0,75 \%$ \\
\hline Proceso judicial por asesinato de un/a sinhogar & 5 & $3,76 \%$ \\
\hline Prostitución & 2 & $1,50 \%$ \\
\hline Rechazo institucional & 5 & $3,76 \%$ \\
\hline Exclusión social & 3 & $2,26 \%$ \\
\hline Reconocimiento institucional & 4 & $3,01 \%$ \\
\hline Trabajo, mundo laboral & 2 & $1,50 \%$ \\
\hline Vagabundo/a, vagabundear... & 1 & $0,75 \%$ \\
\hline Vecinos, movimientos vecinales & 5 & $3,76 \%$ \\
\hline TOTALES & 133 & $100,00 \%$ \\
\hline
\end{tabular}

Otro punto básico, que se hace patente al comenzar a revisar los artículos encontrados sobre el sinhogarismo, es la temática de los mismos. Cuando se escogió la franja temporal de los artículos seleccionados, se procuró englobar tanto el debate sobre la ordenanza de civismo de Barcelona, como la muerte de una mujer sin hogar que tuvo gran repercusión mediática. Si bien no se encontraron un gran número de artículos centrados en dicha ordenanza (dos en el caso de El País, y tres en el caso de El Mundo), la cobertura que ambos medios realizaron del asesinato de la mujer fue muy distinta: 
Tabla 6: Fuente: Elaboración propia.

\begin{tabular}{|c|c|c|}
\hline \multicolumn{2}{|c|}{ No DE ARTÍCULOS DEDICADOS A LA MUJER SINHOGAR ASESINADA EN UN CAJERO $^{\text {EN BARCELONA }}$} \\
\hline & EL PAÍs & EL MUNDO \\
\hline No total & 5 & 29 \\
\hline No $^{\circ}$ artículos/No total de registros $\times 100$ & $23,81 \%$ & $59,18 \%$ \\
\hline
\end{tabular}

Resulta patente la amplia cobertura informativa que prestó El Mundo a dicho asesinato, dado que de la totalidad de artículos encontrados y seleccionados, casi un $60 \%$ de los mismos, estaba dedicado a este caso. Parece entonces evidente que dicha amplia cobertura que se prestó desde El Mundo a este caso, se viese reflejada en la frecuencia con la que encontramos los diferentes códigos en los artículos seleccionados. Los códigos con mayor presencia en El Mundo son curiosamente: "Jóvenes o menores de edad" (9,28\%), "Indigente/s, indigencia..." (9,02\%), "Barcelona" (7,99\%), "Violencia juvenil" (9,28\%) y "Asesinato de un sinhogar" $(7,73 \%)$. Concuerdan a la perfección con los hechos que se relatan en los artículos dedicados a la mujer sinhogar ("indigente" dado que es la forma mayoritaria en ambos periódicos de referirse a las personas en situación de sinhogarismo) asesinada en un cajero en Barcelona, por un grupo de tres jóvenes. Resalta sobre manera la importancia de los códigos "jóvenes o menores de edad" y "violencia juvenil", lo cual hace pensar en la notable cobertura que se le dio en El Mundo a las formas de violencia contra las personas sin hogar perpetradas por jóvenes 0 menores de edad. Por lo que desde la perspectiva de El Mundo, existen dos pilares básicos dentro de la información que mostraron en el intervalo de búsqueda seleccionado: el asesinato de una mujer sin hogar en un cajero de Barcelona, y dentro de la explicación del caso, cobra especial relevancia el hecho de que dicho asesinato fuese cometido por jóvenes; lo cual llevó a crear un código que no existía en el caso de El País, relativo a la "violencia juvenil", asunto que fue tratado reiteradamente como problemática social y analizado en profundidad.

En el caso de este último periódico, El País, la cobertura de dicho asesinato fue menor (tan solo el $24 \%$ de los artículos se centraban en él), lo que debería conducir a una interpretación cauta a la hora de relacionar la frecuencia con que aparecen los códigos y la forma de tratar este caso. Aún así, los códigos más frecuentes son: "Indigente/s, indigencia..." (14,29\%), "Mendigo/s, mendicidad..."(10,53\%), "Barcelona" (8,27\%), y "Jóvenes o menores de edad" $(8,27 \%)$. En esta ocasión la situación es distinta, el sinhogarismo aparece con bastante frecuencia en El País junto con Barcelona como lugar de los hechos relatados o involucrando a las 
instituciones barcelonesas (como podría ocurrir en el caso de hablar de la ordenanza de civismo barcelonesa, o muchos de los casos de acoso y asesinato a personas sinhogar), y los jóvenes o menores de edad como involucrados en los hechos relatados (se utilizó este código para puntualizar si los actores de la historia relatada eran jóvenes o menores, o si se hacía referencia a ellos en un artículo, pero no tiene porqué hacer alusión únicamente a la violencia juvenil). No aparece entre los códigos más utilizados el de "Asesinato de un sinhogar", concordando la información que aporta la frecuencia de los códigos, con ese $24 \%$ de cobertura del caso de asesinato antes concretado. Tampoco cobra especial atención la violencia juvenil como fenómeno y problemática social, por lo que a diferencia de El Mundo, no se vio necesario crear un código referente a este aspecto.

Como última puntualización acerca de los códigos obtenidos del análisis, resultaría muy ilustrativo comentar códigos emergidos a partir de los artículos de un medio no presentes en el otro. Se han escogido códigos con un mínimo de un $5 \%$ de presencia relativa en la totalidad de los mismos, para garantizar cierta relevancia de los comentarios. Se encuentran entonces, dos códigos relativamente presentes en El Mundo, que no encuentran su correlativa presencia el El País: "Violencia juvenil" (comentado con anterioridad) y "Descripción del asesinato, acoso, muerte" $(5,41 \%)$. Este último código se introdujo en referencia a la abundancia de descripciones y detallismo a la hora de relatar el caso en cuestión, ya fuese acoso o asesinato de una persona sinhogar; y al espacio que cubría esta minuciosidad descriptiva en los artículos de El Mundo.

Este último punto, relativo a la forma de tratar, enfocar y expresar los hechos será que el se desarrolle por último, en este apartado.

También resulta de gran relevancia comprobar la existencia y utilización de documentos gráficos (fotografías en su mayoría) a la hora de tratar el tema del sinhogarismo. En la tabla siguiente se presentan los datos sobre la cantidad de ilustraciones encontradas en los artículos seleccionados: 
Tabla 7: Fuente: Elaboración propia. ${ }^{7}$

\begin{tabular}{|c|c|c|}
\hline \multicolumn{3}{|c|}{ No FOTOGRAFÍAS O ILUSTRACIONES } \\
\hline No total & EL PAÍs & EL MUNDO \\
\hline No ilustraciones/artículos* & 5 & 16 \\
\hline
\end{tabular}

*Calculado en base a la totalidad de registros encontrados: 21 en el caso de El País, y 49 en el caso de El Mundo.

Se aprecia cómo El Mundo hace ligeramente un mayor uso de las fotografías y material gráfico para ilustrar sus noticias, del orden de un $10 \%$ mayor. Como ejemplo clarificador, el 22 de diciembre, El Mundo publicó un artículo en que se exponían varios fotogramas que relataban minuciosamente el asesinato de la mujer, obtenidos gracias al vídeo de la cámara de seguridad del cajero donde pereció dicha persona sin hogar. Seguido de estos tres fotogramas, El Mundo ofrecía un artículo bajo el titular "Cronología de un crimen brutal, segundo a segundo", en el que se describían "los fragmentos más destacados de la filmación del cajero automático" ${ }^{8}$, y se ofrecían con horas, minutos y segundos, todo lo que fue sucediendo durante el asesinato, que quedó plasmado en la grabación.

Esto lleva a poner de relevancia otra de las diferencias en el tratamiento de la información por parte de un periódico u otro. Fruto de la gran cobertura que El Mundo ofreció del citado asesinato, se encuentra en sus artículos un gran detallismo (como se vio con anterioridad) y una gran minuciosidad en las descripciones. El ejemplo de este punto lo tenemos en la siguiente cita:

"Los médicos y policías encontraron tu cuerpo tan ennegrecido que al principio pensaron que eras subsahariano. Las ratas, implacables, te habían devorado parte de la cara. El cuchitril donde vivías estaba lleno de cartones. Seguramente eran tu cama. Unos restos de varias hogueras lo manchaban todo de negro, convertían tu hogar en un sitio polvoriento, en medio de ninguna parte". (Herraiz, Pablo (2006). "Un indigente muere de frío en Aranjuez". En: El Mundo s.XXI, 6 de febrero de 2006, sucesos, p.8)

\footnotetext{
7 Resulta importante resaltar que algunos de los artículos encontrados en la hemeroteca estaban en formato Word. Ninguno de los artículos en Word estaba provisto de fotografías. Doy por hecho que ninguno de ellos tenia grafismos en la edición del periódico.

8 "Cronología de un crimen brutal, segundo a segundo". En: El Mundo s.XXI, jueves 22 de diciembre de 2005, España, p.21.
} 
De todo ello también se deriva el gran peso que tiene el código "perfil de los acusados, agresores..." en El Mundo $(3,61 \%)$ en comparación con la frecuencia del mismo código en El País $(0,75 \%)$. También resulta interesante analizar el foco de atención a la hora de desarrollar descripciones, algo que puede hacerse atendiendo a los códigos "perfil Sinhogar" y "perfil de los acusados, agresores...".

Tabla 8: Fuente, elaboración propia

\begin{tabular}{|c|c|c|}
\hline & EI Mundo & EI País \\
\hline "Perfil Sinhogar" & $1,03 \%$ & $1,5 \%$ \\
\hline "Perfil de los acusados, agresores..." & $3,61 \%$ & $0,75 \%$ \\
\hline \% códigos relativos a "perfiles" & $4,64 \%$ & $2,5 \%$ \\
\hline
\end{tabular}

Se puede apreciar cómo existen dos grandes diferencias entre ambos periódicos a la hora de desarrollar perfiles descriptivos de actores clave: El Mundo era más propenso que El País a desarrollar perfiles, casi el doble (4,64\% frente al 2,5\%). Por otra parte, dentro de los perfiles que cada periódico desarrollaba, El Mundo tendía a centrarse en el perfil de los acusados o agresores (en todos los casos eran jóvenes y menores de edad); y El País al contrario, resultaba más propenso a delinear perfiles relativos a las personas sinhogar (que por las temáticas tratadas, eran casi en su totalidad las víctimas de agresiones, acoso o asesinato).

Para terminar este apartado, se hace necesario poner de relevancia, las referencias que se encontraron en El Mundo a los juicios de valor, y la mayor politización de los asuntos tratados. En los artículos se encuentran afirmaciones del tipo:

- "Quemar ancianas está directamente relacionado con la ley educativa de los socialistas que no quiere deprimir a los educandos imponiéndole límites y sanciones. Mejor para los padres que no hablan son sus hijos y encierran los principios en el cajón del televisor". (Prieto, Martín (2005). "Cibercafé, horror show". En: Bajo el Volcán. El Mundo s.XXI, 24 de diciembre de 2005, opinión, p.2).

- "No acumulo el suficiente morbo para escuchar el testimonio, o los intentos de justificación, o el presumible e infinito dolor de un hombre hablando sobre el monstruo que engendró. El Mal en estado puro existe, no hay que remitirse al pasado, a la notoriedad de asesinos en serie, o selectivos como Hitler y Stalin. El más demoníaco grado de horror es apalear a una mendiga y quemarla viva". (Boyero, Carlos (2005). "Todos felices menos la mendiga". En: El Mundo s.XXI. 23 de diciembre de 2005, comunicación, p.63). 
Por su parte, El País es más propenso que El Mundo a dar un enfoque judicial y a dar una mayor cobertura a los procesos judiciales derivados de agresiones y asesinatos que El Mundo. Ello se deriva de la mayor presencia del código "proceso judicial por asesinato de un/a sinhogar" (un 3,76\% frente a un 2,06\%). Además, en El País eran menos explícitos a la hora de realizar críticas políticas de problemáticas sociales, poniendo frecuentemente la crítica en voces de terceras personas:

- "Consuelo Orias, concejal del PSPV en el Ayuntamiento de Valencia, fue la encargada de denunciar la carga del servicio de limpieza en compañía de una dotación de la Policía Local contra indigentes y prostitutas...". (L. Garrido (2005). "La policía local de Valencia desaloja a indigentes en Velluters a manquerazos". En: El País, 6 de diciembre de 2005, Comunidad Valenciana, p.6).

- "Para Cáritas, la situación creada a este indigente, siendo grave, es una muestra de lo que puede ocurrir al aplicar una ordenanza cívica que, afirmó un portavoz de la institución, no distingue entre casos muy diferentes entre sí. (Arroyo, Francesc (2006). "El Ayuntamiento de Barcelona embarga la cuenta a un mendigo". En: El País, 4 de febrero de 2006, Cataluña).

\section{Segunda etapa del análisis: el análisis reticular}

En este apartado se realizará un estudio reticular de los códigos resultantes del análisis de contenidos. Como se apuntó anteriormente, la forma en que se establecieron las relaciones entre códigos fue en base a su co-presencia en el mismo artículo. El resultado fueron dos redes de códigos, una en base a los artículos encontrados en El País y otra para los artículos encontrados en El Mundo. En lo que consistirá este punto, es en el análisis de las redes obtenidas, a partir de los gráficos y los diferentes coeficientes que facilitan el análisis de redes.

El análisis comienza, de esta forma, presentando las dos redes obtenidas. Puntualizar que se ha asignado un atributo a los códigos, para diferenciar aquellos nodos que contaban con más de un 3\% de presencia relativa en los artículos (tablas 4 y 5), de los que suponían una presencia relativa baja (se considerará bajo un porcentaje menor del $3 \%$ ). Lo que podría verse como una distinción entre los asuntos centrales de cada marco cultural, y los aspectos tratados residualmente. 
Gráfico 1: Red de El País (fuente: Elaboración propia).

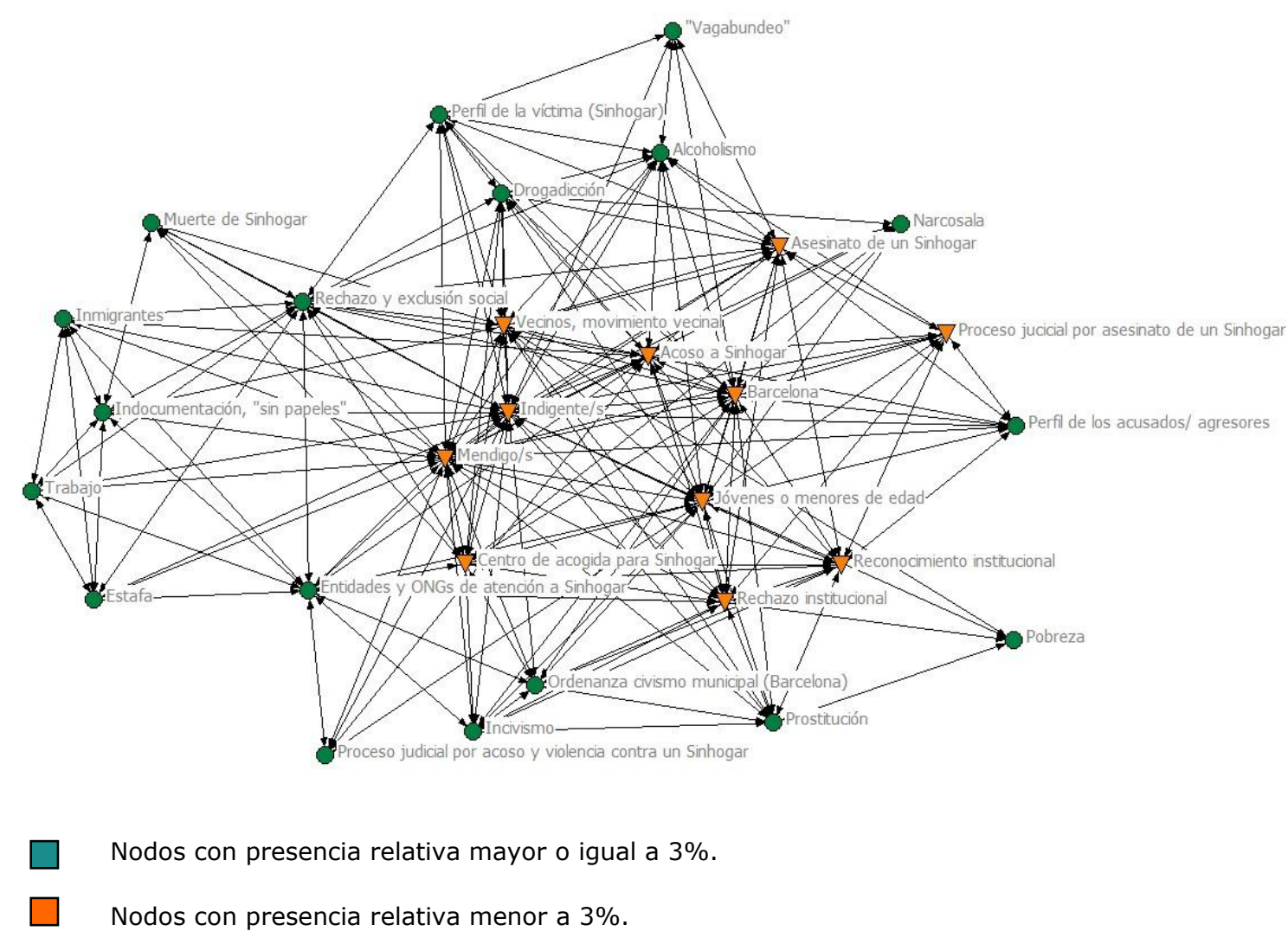

Se pueden observar dos grafos binarios de relaciones simples: sólo hay dos posibilidades de relación sin graduación posible, co-presencia en al menos un artículo (relación positiva o existencia de relación), y no co-presencia en ningún artículo (relación negativa o ausencia de relación). Por otra parte, el tamaño de cada red es ligeramente diferente. Si bien en el caso de la red de El País estaríamos ante una red del tamaño de 29 nodos y 812 relaciones posibles; en el caso de El Mundo, la red constaría de 930 relaciones posibles entre 31 nodos o códigos existentes. Ésta última red, entonces, abre muchas más posibilidades de relación y resulta ligeramente más compleja que la primera (resultado también de una muestra de artículos mayor, y por tanto, una mayor cobertura de este fenómeno por parte de El Mundo). 
Gráfico 2: Red El Mundo (fuente: elaboración propia).

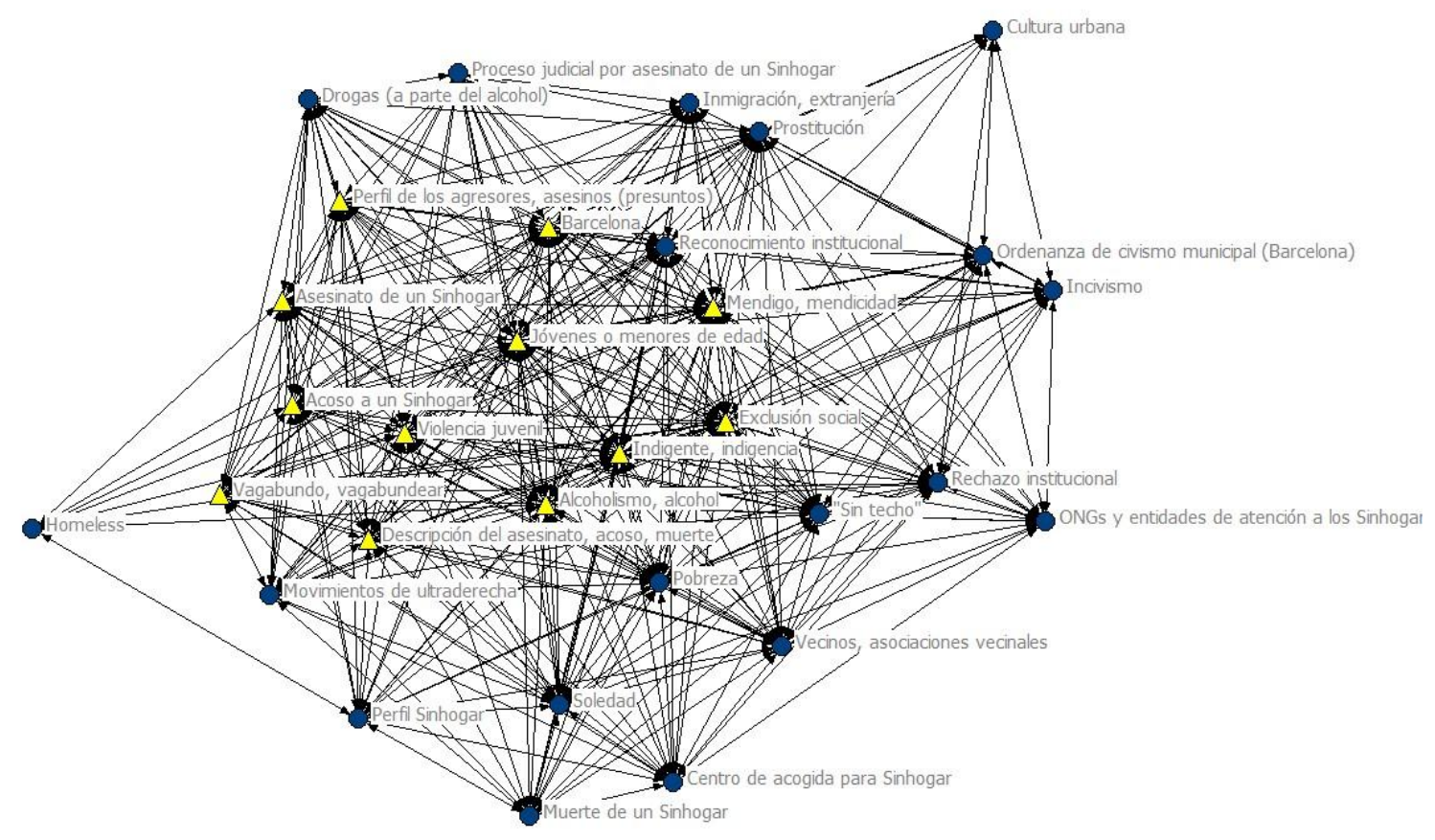

Nodos con presencia relativa mayor o igual a $3 \%$.

Nodos con presencia relativa menor a $3 \%$.

Centrando el análisis en la densidad de las redes, es decir, en cuan cohesionadas o concentradas están, decir que El Mundo parece tener una red mucho más densa, ya que presenta un 69'35 \% de las relaciones posibles entre sus nodos, frente al $43^{\prime} 84 \%$ de relaciones existentes ante las posibles, que se encuentran en la red de El País. Esto podría llevar a pensar que los códigos del El Mundo están mucho más relacionados y presentan más co-presencias en los artículos entre la totalidad de ellos que los de El País. Teniendo en cuenta que hablamos de marcos culturales, los asuntos tratados por El Mundo representan un marco cultural fuerte a la hora de tratar el tema del sinhogarismo, más que tratarse de múltiples perspectivas de tratar el fenómeno dentro del propio medio.

Se corrobora con la distancia geodésica el punto anterior, puesto que la red de El Mundo tiene una distancia geodésica media menor que la de El País, 1,306 de El Mundo frente a 1,562 de El País. Es decir, si en El Mundo 1,306 pasos es el camino más corto y eficiente de ir de un nodo (o código) a otro; en el caso de El País, el camino medio más rápido es de 1,562 pasos. Por lo que de nuevo se podría afirmar que la red de El Mundo es ligeramente más densa que la de este otro periódico, 
aunque las diferencias son muy pequeñas puesto que el diámetro de ambas redes es idéntico (del orden de dos pasos son necesarios en las dos redes para ir de un nodo a otro). Se está entonces, ante códigos bastante cohesionados, lo cual interesa para obtener marcos culturales eficientes y coherentes sobre sinhogarismo. Este punto garantiza la existencia de un único marco cultural por cada medio de comunicación, corroborando la hipótesis de partida del estudio: efectivamente cada uno de los medios analizados posee una perspectiva o marco unificado de tratar la temática del sinhogarismo. Se reafirma este punto con los datos de la accesibilidad, que en ambos casos es máxima: no se encuentran subgrupos sin relaciones entre los códigos, ni divisiones aparentes; si no redes compuestas por un único componente. De nuevo es una buena noticia, ya que lo que se pretende es acceder a un conjunto de códigos lo suficientemente posible relacionados como para formar un marco cultural coherente; y este supuesto se cumple, ya que en ambas redes todos los nodos están conectados con todos los nodos.

La centralidad de grado viene a reafirmar esta tendencia, aunque en conjunto la red de El País parece estar más jerarquizada que la de El Mundo, con un grado de $58,163 \%$ de jerarquización frente a $31,634 \%$. Es decir, en referencia a las máximas redes jerarquizadas en cada caso, la red de El País se asemejaría más a la hipotética red lo más jerarquizada posible. Esto hace pensar que el poder entre los nodos está menor repartido y más concentrado en determinados nodos, siempre en comparación con El Mundo. Ello podía explicar por qué la red de El Mundo está ligeramente más cohesionada, lo cual, una vez más, podría deberse a la amplia cobertura del caso del suceso de la mujer sin hogar que se dio desde este periódico. A pesar de las direfencias, se observa también con la centralidad medida a nivel meso, que ambas redes, una vez más, reunen toda una serie de fenómenos interpretativos muy interrelacionados entre ellos, que forman un marco cultural más coherente y multidimensional. Siguiendo el hilo de los indicadores de centralidad, y midiendo ésta actor por actor y en relación a la frecuencia de los códigos (mayor o menor del 3\%), se puede hablar de los asuntos fuertes y de mayor poder simbólico dentro de cada marco. En El Mundo, los nodos con mayor grado de centralidad parecen congeniar dentro del grupo de códigos con una frecuencia relativa mayor del 3\%: Barcelona, exclusión social, alcohol, indigente /s e indigencia, jóvenes o menores de edad y mendigo/s o mendicidad. En el País, ocurre algo similar, coincidiendo los códigos con mayor grado de centralidad, con los códigos de frecuenta relativa grande. Aunque en este segundo caso se ha de puntualizar que existe un salto comparativo entre los nodos "indigente/s, indigencia..."(100) y "mendigo/s, mendicidad..." $(92,857)$ y el resto; por lo que se 
comprende esa mayor varianza de los datos relativos a la centralidad dentro de esta red, dado que estos dos códigos presentan una centralidad significativa respecto al resto, lo cual se explica, ya que estos códigos ejercieron el papel de motores de búsqueda en el muestreo de artículos. Las centralidades de El Mundo por el contrario, hablan otra vez de códigos con un grado de centralidad con menos variabilidad interna, una red más densa sin nodos con grandes centralidades jerárquicas respecto al resto.

A partir de la información que aportan las cliques, $\mathrm{n}$-cliques y $\mathrm{k}$-cores se ejemplifica una vez más, a través de estos indicadores, la gran cohesión interna de ambos marcos culturales, haciendo algunas puntualizaciones. La visión que ofrece la idea de los K-cores, es decir, la idea del número máximo de lazos comunes entre los nodos siempre que formen un componente y éstos se puedan comunicar entre ellos; habla de la gran cohesión de la red de El Mundo (subdividida en 3 clusters) en relación a la de El País (con 5 clusters). Siempre teniendo en cuenta lo cohesivas que son ambas de por sí, y la disminución de cohesión interna de los clusters según se baje de nivel de exigencia (derivado del propio método de formación de los clusters). Sobre la composición de estos clusters, decir que están formados en ambos casos por conjuntos amplios de códigos, algo que se repite con las cliques y las n-cliques, y que aporta una idea de unos marcos culturales y formas de tratar el sinhogarismo multidimensionales y con múltiples argumentos y puntos de referencia.

Teniendo en cuenta solamente el primer corte y por tanto el primer cluster, dadas sus dimensiones, dentro del marco cultural de El País, quedarían fuera del grupo principal de asuntos claves tratados fenómenos como la pobreza, la inmigración, el mundo del trabajo, la indocumentación, o las problemáticas de las narcosalas. Por otra parte, dentro del principal cluster de El Mundo, queda fuera la problemática de la ordenanza municipal barcelonesa y el debate del incivismo (algo que cobra importancia en El País), muy relacionado con la forma que tenían de hablar de cultura urbana en este medio, que por cierto, también queda excluida del principal cluster, junto con las formas secundarias de hablar de sinhogarismo: "vagabundo/s", "personas sin hogar" o "homeless". La perspectiva de las cliques (la idea de grupos más cercanos internamente que con el resto de los nodos de la red), ofrece un panorama parecido: en lo referente a los últimos códigos, es decir, los que tienen patrones de copresencias más diferentes al resto; en El País encontramos códigos como: "Proceso judicial por acoso a Sinhogar", "Pobreza", "Perfil de la víctima o Sinhogar", "Narcosala", "Muerte de Sinhogar" o "vagabundo/s". Por otra parte, en El Mundo se encuentra: "Personas sin hogar", 
"Cultura urbana", "Homeless", "drogas" o "Perfil Sinhogar". Se podría afirmar que en ambos casos, existen códigos con una frecuencia menor de aparición en los artículos (los descritos anteriormente), y que además tienen patrones de relación con el resto diferentes, que caracterizan las visiones de cada periódico: El País trata de forma secundaria temas como el de las narcosalas, y le otorga más importancia a los juicios por acoso a una persona sinhogar; mientras que El Mundo habla en un segundo plano de la cultura urbana, y utiliza conceptos más especializados para tratar el tema como "homeless" o "Personas sin hogar".

También resulta útil el enfoque de las $n$-cliques para seguir con este tipo de análisis; puesto que dentro de estas diferencias encontradas en los marcos culturales y sobre los asuntos que les dan forma, este indicador recuerda la gran cohesión interna de ambas redes, ya que desde esta perspectiva, solamente existe una 2-clique. Es decir, todos los códigos están interconectados por un máximo de 2 conexiones. Lo que quiere decir que la relación de copresencia entre los códigos es máxima, puesto que si no coinciden en el mismo artículo, alguno de los códigos con el que sí lo hacen, está presente en el mismo texto con cualquiera del resto de códigos.

A la hora de examinar las distancias geodésicas concretas de un nodo a otro (el camino más corto de un código a otro), resulta que hay códigos (la gran mayoría) relacionados entre ellos en tan solo un paso, es decir, todos los nodos pueden alcanzar el resto de nodos. Aunque curiosamente en la red de El País los caminos geodésicos entre sus códigos son bastante cortos y eficientes, llegando en contadas ocasiones a los 10 pasos; mientras que para El Mundo, los códigos peor "situados" (desde el punto de vista de la accesibilidad geodésica) aunque sean pocos, se encuentran a 18 y 19 pasos de algunos otros (como la distancia geodésica de inmigración a prostitución, o entre "Sin techo" y movimientos de ultraderecha). Es decir, los asuntos tratados en El País, forman un marco cultural que aunque no de forma muy cohesiva, tienen bastante interrelación entre los mismos; mientras que en El Mundo, se encuentra cierto núcleo de códigos con una cohesión mayor, habiendo ciertos asuntos que quedan a cierta distancia respecto del grupo principal (con los datos que tenemos del Análisis de Contenidos, esto podría deberse a ese casi $60 \%$ de artículos basados en el asesinato de la mujer sin hogar).

Llegado este punto se analizarán las redes resultantes desde el punto de vista de la composición de grupos por equivalencias. Desde este enfoque, lo que pasaría a interesar es la similitud entre códigos, es decir, si un código podría llegar a resultar intercambiable por otro dentro de la red, según su posición en ésta y su patrón de 
relaciones o co-presencias. Dentro esta visión, se comenzará con la equivalencia estructural, que se centraría en decir hasta qué punto dos códigos resultan sustituibles, gracias a las similitudes de sus patrones de relaciones con el resto. Comenzando con el caso de El País, los primeros casos de equivalencia estructural, se caracterizan por hacer referencia a códigos prototípicos de El País (no presenten muchos de ellos en El Mundo): Estafa, trabajo, incivismo y ordenanza civismo de Barcelona. En concreto, los casos de estafa y trabajo hacen referencia a artículos que relatan casos solo cubiertos por El País. Si se amplia el proceso de aglomeración aparece otro código minoritario (menor del 3\% de presencia relativa): inmigración. En un principio, se encuentran códigos de presencia relativa baja que podrían ser intercambiables. Esta tendencia se explica fácilmente dado que se ha ido codificando conforme se repetían las problemáticas, y en base de los motores de búsqueda que indicamos anteriormente. Por ello los códigos de mayor equivalencia estructural serían los de menor presencia relativa. Fijando la vista en las equivalencias estructurales de El Mundo ocurre el mismo fenómeno con los dos primeros códigos de la equivalencia estructural: "incivismo" y "ordenanza municipal de civismo de Barcelona"; lo cual resulta más que evidente ya que hacen referencia a dos dimensiones de la forma en que los artículos hablaban del "civismo". Los últimos códigos y de más complicada equivalencia estructural, hacen referencia a problemáticas muy específicas como "cultura urbana", o a categorizaciones de personas sin hogar muy minoritarias como "homeless" o "persona sin hogar"; lo cual hace pensar que podrían formar parte de un fenómeno con jerga propia y categorizaciones específicas, que hacen difícil la posibilidad de hablar de equivalencia con otros códigos más frecuentes, en estos casos.

Se terminará este análisis de redes con algunas de las ideas claves dilucidadas. La primera es un punto clave, la perspectiva reticular dice que efectivamente los asuntos tratados y codificados en la etapa anterior, forman un conjunto lo suficientemente coherente y cohesionado como para hablar de marcos culturales. A grandes rasgos, la gran cobertura al fallecimiento de la mujer sin hogar por parte de El Mundo junto con otros aspectos estructurales, hacen del marco cultural reticular que utiliza este periódico un conjunto muy cohesionado y fuerte de principios, opiniones y visiones sobre el sinhogarismo; aunque con asuntos tratados de forma residual y a gran distancia del poder simbólico del núcleo principal. El País por su parte, de la misma forma que se presenta como un marco con una gran coherencia interna, también da síntomas de aglutinar asuntos y códigos ligeramente más heterogéneos que en el caso de El Mundo, dado que presenta cierta diferencia entre la presencia de los códigos motores de búsqueda y el resto. 


\section{En conclusión}

Como resultado de esta pequeña investigación, se podría concluir que se han encontrado dos formas y marcos culturales diferenciados de orientar, organizar, tratar, argumentar, comentar e interpretar la información relativa al sinhogarismo en estos dos medios de comunicación de prensa mayoritaria. Poniéndo el énfasis en las diferencias, se puede decir que se encuentran dos marcos culturales diferenciados no tanto en el contenido de la información, sino en la forma de presentarla y tratarla. El análisis de contenidos ha permitido analizar estas desigualdades en lo referente a la omisión de asuntos dentro de los mismos marcos, así como a la hora de juzgar, presentar y racionalizar el fenómeno.

Se podría decir que dentro de ambos medios, los marcos culturales se basan justamente en estrategias invisibilizadoras distíntas. Los contenidos de fondo se parecen, puesto que ningún marco cultural llega a romper cierta estereotipación social del sinhogarismo, pero las estrategias de representación y formas de organizar y juzgar el contenido difieren. Si bien El Mundo, como se ha visto, hace un uso más "espectacular" (en su mayor uso de fotografías, por ejemplo), con juicios de valor y crítica política abierta; El País opta por una visión superficial del tema, ello se ejemplifica en el uso que se hace de los recursos judiciales y las opiniones en boca de terceras personas. Este medio no se centra tanto en el caso de la mujer sin hogar barcelonesa, pero abarca más sucesos relacionados con el acoso físico y psíquico a las personas sin hogar. Quizá por ello llega a dar cobertura a un amplio espectro de problemáticas sociales asociadas al sinhogarismo como la inmigración, la ordenanza de civismo de Barcelona o la pobreza; pero siempre de forma residual y sin llegar a romper el estereotipo de la "indigencia".

Por otra parte, decir que El Mundo realizó una amplísima cobertura del asesinato de una mujer sin hogar en un cajero de Barcelona, por parte de un grupo de jóvenes. Este punto marca ampliamente su visión del sinhogarismo, pero resultan más importantes las ausencias a la hora del tratamiento de esta información. El foco de atención se pondrá en los autores de la agresión más que en la víctima. El sinhogarismo resulta invisibilizado en sí mismo, llegando a ser una excusa para tratar el fenómeno de la violencia juvenil, depurando incluso responsabilidades políticas al respecto de tal violencia, evadiendo la problemática social de las personas sin hogar. De ello se deriva un mayor uso de los recursos gráficos que generan impacto sobre los casos, e incluso el desarrollo de detallismo y la minuciosidad a la hora de tratar los sucesos que incumbían a las personas sin hogar; sin entrar en orientaciones sociales y sociológicas en profundidad sobre este 
fenómeno social. La estereotipación social del sinhogarismo juega un punto clave, marcando una barrera de la que no se va más allá, incluso cuando tiene lugar un suceso como el que se cubre, de gran repercusión mediática y social.

Para terminar se ha dejado lo que se considera es el plato fuerte del análisis. Si hay un punto en común en ambos marcos culturales analizados, éste se puso de relieve a la hora de fijar el método de búsqueda y selección de los artículos. La tendencia básica de ambos medios habla de un imagiario colectivo de fondo, para el cual el sinhogarismo hace referencia en exclusiva a las personas llamadas "sin techo" en base al ETHOS antes comentado; además de mencionar reiteradamente el sinhogarismo bajo las acepciones de indigencia y mendicidad (aunque El Mundo tuvise un espectro y nomenclatura un poco más amplios, no escapaba de la estereotipación del fenómeno). Es decir, socialmente, decir exclusión residencial parece aludir únicamente y bajo marcadas etiquetas sociales a las personas que la sufren de forma extrema (que pernoctan en la espacios públicos...); obviando muchos colectivos que sufren este tipo de exclusión bajo otras formas: habitáculos inadecuados (chabolismo...), alojamientos temporales, resicencia en albergues o instituciones sociales temporales, personas que habitan en viviendas inseguras en cuanto al régimen de tenencia (embargo o amenaza de él...) o bajo amenaza de violencia física (mujeres maltratadas...); y un sinfín de situaciones de exclusión residencial que parecen ser socialmente invisibles e invisibilizadas. En palabras de Doherty:

"Cualquier tipología sobre el problema de la vivienda cuestiona las maneras más arraigadas de enfocar el problema y choca, implícitamente y explícitamente con intereses propios. Por ejemplo, las autoridades locales, carentes de fondos, responsables de solucionar el problema de la vivienda pueden no querer adoptar una definición tan amplia del sinhogarismo ya que a su vez se ampliaría su esfera de responsabilidades" (Doherty, 2005: 48).

Con esto se viene a decir, que uno de los puntos significativos del análisis es previo y trasciende la idea de marco cultural, ya que se encuentra presente en ambos marcos. El imaginario colectivo sobre las personas sin hogar, se presenta bajo un compendio de etiquetas sociales y denominaciones como se ha visto de "vagabundeo", "mendicidad" o "indigencia"; reduciendo la misma exclusión residencial a sus rasgos más extremos y estereotipados, y obviando las implicaciones políticas y sociales de fondo que tiene este fenómeno. 


\section{Agradecimientos}

Me gustaría agradecer a Joan Miquel Verd todo su apoyo, asesoramiento y las numerosas revisiones que realizó del artículo original.

\section{Referencias bibliográficas}

Andréu Abela, J. (1998). Las técnicas del análisis de contenido: una revisión actualizada. [Documento en línea]. Disponible en: http://public.centrodeestudiosandaluces.es/pdfs/s200103.pdf [Consulta: 2010, diciembre 14].

Cabrera Cabrera, Pedro José (2008). "La acción social con personas sin hogar en la España del siglo XXI. Avances y retos en la última década". En: Laparra Navarro, Miguel; Perez Eransus, Begoña. Exclusión Social en España: un espacio diverso y disperso en intensa transformación, Cáritas Española, pp. 173-219.

Cabrera Cabrera, Pedro José; Rubio, Maria José (1998). "Las persona sin hogar hoy". En: Revista del Ministerio de Trabajo e Inmigración, no 75, pp. 51- 74.

Doherty, Joe (2005). "El origen del sinhogarismo: perspectivas europeas". En: Documentación Social, no 138, julio-septiembre, pp. 41-61.

Hanneman, Robert A (2000). "Introducción a los métodos de análisis de redes sociales". En: Departamento de Sociología de la Universidad de California Riverside. [Documento en línea]. Disponible en: http://www.redessociales.net/materiales [Consulta: 2009, noviembre 08].

Lozares, Carlos (2000). "El discurs reticular, més enllá de la classificació". En: Revista Catalana de Sociología, n¹1, pp. 183-189.

Lozares, Carlos; Verd Pericàs, Joan Miquel; Martì Olivé, Joel; López Roldán, Pedro (2003). "Relaciones, redes y discurso: revisión y propuestas en torno al análisis reticular de datos textuales". En: Reis, Revista Española de Investigaciones Sociológicas, nº101, pp. 175-200.

Mayring, Philipp (2004). "Qualitative Content Analysis". En: Uwe, Flick; Ernst Von Kardorff; Ines Steinke. A comparion to Qualitative Research, Londres: Sage, p. 266. 
Verd Pericás, Joan Miquel (2005). "El uso de la teoría de redes sociales en la representación y análisis de textos. De las redes semánticas al análisis de redes textuales". En: Empiria, Revista de Metodología de Ciencias Sociales, №10, julio-diciembre, pp. 129-150.

Tábara, Joan David; Costejà, Meritxell; Van Woerden, Fincent (2004). "Las culturas del agua en la prensa española. Los marcos culturales en la comunicación sobre el Plan Hidrológico Nacional". En: Papers 73, pp. 153-179.

W. Bauer, Martin. (2000). "Classical Content Analysis: a Review". En: Qualitative Researching with text, image and sound, Londres, Sage, pp. 131-151. 